\title{
Using fear appeal theories to understand the effects of location information of patients on citizens during the COVID-19 pandemic
}

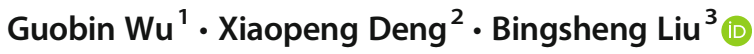 \\ Accepted: 31 May 2021 \\ (C) The Author(s), under exclusive licence to Springer Science+Business Media, LLC, part of Springer Nature 2021
}

\begin{abstract}
During the COVID-19 pandemic, understanding the effects of location information of patients has significant theoretical and practical implications for public crisis management and health communication. Based on fear appeal theories, this research proposed a chain reaction model that links physical distance to the nearest patients, which is informed by the location information of patients, citizens' anxiety, attention to information and preventive behaviors. To test the hypothesized model, we conducted a study during the COVID-19 outbreak in mainland China in March 2020. The survey of 2061 people from 244 cities across 30 provinces showed that physical distance to confirmed cases has a significant influence on citizens' anxiety, which in turn can improve their preventive behaviors through the mediating factor of attention to information. In addition, this research also revealed the twofold effects of vertical collectivism as a personality trait on anxiety. These findings will provide support to help governments take actions to reduce citizens' anxiety and promote preventive behaviors.
\end{abstract}

Keywords COVID-19 $\cdot$ Physical distance $\cdot$ Anxiety $\cdot$ Preventive behaviors $\cdot$ Fear appeal theories $\cdot$ Location information

\section{Introduction}

In December 2019, the first group infected with the coronavirus disease (COVID-19) was identified in Wuhan, Hubei Province, China (Wu \& McGoogan, 2020), and COVID-19 has since become a public health emergency of global concern (Wang, Pan, Wan, Tan, Xu, Ho, et al., 2020). On March 11, the World Health Organization (WHO) declared COVID-19 a pandemic (WHO, 2020). During this crisis, many countries

Bingsheng Liu

bluesea_boy_1979@163.com

Guobin $\mathrm{Wu}$

wuguobin001@126.com

Xiaopeng Deng

dxp@seu.edu.cn

1 College of Management and Economics, Tianjin University, 92 Weijin Road, Nankai District, Tianjin, People's Republic of China 300072

2 School of Civil Engineering, Southeast University, Nanjing, 2 Southeast University Road, Jiangning District, Nanjing, Jiangsu Province, People's Republic of China 211189

3 School of Public Affairs, Chongqing University, 174 Shazheng Street, Shapingba District, Chongqing, People's Republic of China 400044 have taken decisive actions. For example, China sealed off Wuhan city on January 23 and shut down public transport in eight other cities to minimize the spread of the virus near the epicenter (Tuo et al., 2020). Moreover, to better control the pandemic, governments worldwide have imposed social distancing by closing schools or public places, cancelling mass events, and promoting remote work (Bayham \& Fenichel, 2020). Unprecedented actions have dramatically altered the public's ordinary lives, causing fears and influencing the behavior of people everywhere (Rochadi et al., 2020).

To improve the awareness of the self-protection of citizens (Adhikari et al., 2020), especially those whose neighbors are confirmed patients, governments around the world promptly communicate real-time confirmed case information ( $\mathrm{Li}$, Chen, et al., 2020). For example, China's governments at all levels publish newly confirmed cases and their distribution in the official media every day. The Singaporean government released a mobile phone app called TraceTogether that publishes real-time information about the COVID-19 pandemic, including the locations of patients, so that residents can understand the situation around them (Cho et al., 2020). When a person tests positive, the local governments of South Korea send out an alert to people living nearby about that person's movements (Zastrow, 2020).

This real-time case information released by local governments can help citizens to be clear about the spread and 
development of the pandemic (Bento et al., 2020) and the location of the cases nearest their residence. Especially for uninfected people, the location information of patients nearest where they live is important information that has considerable impacts on their emotions, attention to information, and behaviors during pandemics. For example, during the H5N1 pandemic, people at a shorter physical distance to confirmed cases showed a higher degree of negative affect, such as panic (Manabe et al., 2012). The first reported local COVID-19 case can induce local citizens' attention to pandemic information (Bento et al., 2020). In addition, during outbreaks of avian influenza, citizens who are informed of local outbreaks adopt more preventive behaviors (Kuo et al., 2011).

Although the influencing factors of citizens' anxiety, attention to information and preventive behavior have been widely explored during the COVID-19 pandemic, the possible effects of location information of patients on these psychological and behavioral reactions remain unclear. Understanding the effects of location information can be of great help in helping governments manage the emotions and behaviors of citizens who are physically closer to confirmed patients, thus realizing better pandemic management. For example, identifying the sources of people's anxiety can directly inform the development of psychological interventions that can minimize anxiety during the COVID-19 outbreak and provide guidance for stimulating preventive behaviors throughout the remainder of the pandemic (Wang, Pan, Wan, Tan, Xu, Ho, et al., 2020). Therefore, both scholars and practitioners are faced with the following question:

RQ: How does location information of patients, particularly physical distance to the nearest patients, influence citizens' anxiety, attention to information and preventive behaviors in a pandemic?

To address the above question, we involved fear appeal theories in this research. Fear appeal theories posit that the threat information of a disease elicits fear or anxiety, and fear or anxiety in turn motivates people to pay attention to related information and initiate behavioral changes to protect themselves (Floyd et al., 2000; Kok et al., 2014; Ling et al., 2019). For example, based on fear appeal theories, Du et al. (2020) found that increased information about prevalence rates of COVID-19 was associated with more searches for protective behaviors of the public, and Scopelliti et al. (2021) emphasized that moderate levels of fear have increased the public's preventive behaviors in the use of public spaces during the COVID-19 pandemic. Therefore, we believe that fear appeal theories can also help us explore the effects of information about the location of patients.

This research proposes several specific hypotheses based on fear appeal theories and tests the hypothesized relationships based on data collected from online questionnaire surveys completed by Chinese citizens during the peak period of the COVID-19 pandemic in China. We hope this research can contribute to the literature in three primary ways: i) $\mathrm{We}$ reveal the effects of location information of patients (i.e., physical distance to patients) on citizens during the COVID19 outbreak, which will help health communication researchers comprehensively understand the effects of pandemic information released by local governments during a public health crisis; ii) We contribute to fear appeal theories by confirming the effects of vertical collectivism as a personality trait on citizens' anxiety; and iii) We investigate the potential influencing factors of people's anxiety and preventive behaviors, which can help crisis management researchers understand the causes of anxiety and preventive behaviors during pandemics. From a practical perspective, this research provides guidance for practitioners regarding the release of pandemic information, especially regarding the location of confirmed cases of COVID-19.

\section{Theoretical Background and Hypothesis Development}

\section{Fear Appeal Theories}

Fear appeal theories have been widely used in behavioral change interventions in the field of health management to explore the effects of threat information on individuals' protective actions (Floyd et al., 2000; Ruiter et al., 2014; Scopelliti et al., 2021). Fear appeal theories include two predominant theoretical frameworks: protection motivation theory (PMT) and the extended parallel process model (EPPM) (Ruiter et al., 2014). PMT proposes four message factors of information: (a) the magnitude of noxiousness of a depicted event; (b) the probability of occurrence; (c) response efficacy depictions; and (d) self-efficacy depictions (Rogers, 1975; Maddux \& Rogers, 1983). The above four factors will influence individuals' attitude changes (i.e., intent to adopt a recommended response) through cognitive mediating processes of their perceived severity, perceived susceptibility, perceived efficacy of coping response and perceived self-efficacy, as well as protection motivation (Rogers, 1975; Maddux \& Rogers, 1983).

The EPPM proposed by Witte (1992) advances previous fear appeal theories, especially Rogers' PMT (Maddux \& Rogers, 1983; Rogers, 1975), in three ways. First, EPPM demonstrates that fear appeals fail because PMT only takes into account danger control processes but not fear control processes, which lead to message rejection. Second, EPPM reincorporates fear as a central variable that links perceived threat (i.e., susceptibility and severity) and perceived efficacy (i.e., self-efficacy and response efficacy) to protective and defensive motivations in the cognitive mediating processes. 
Third, EPPM proposes that individual differences (e.g., personality and prior experience) influence the appraisal of threat and efficacy. Based on the original EPPM, many researchers further specified and revised this model. For example, So (2013) proposed an extension of the extended parallel process model (E-EPPM), which incorporates a more comprehensive perspective on risk perceptions as a construct involving both cognitive and affective aspects (i.e., fear and anxiety). Through an empirical study, So et al. (2016) proved that a high threat message would induce both fear and anxiety. In addition, they found that anxiety led to a higher level of motivation to obtain information than fear, and paying attention to information was one of the significant predictors of intention to take protective action (So et al., 2016).

Overall, according to fear appeal theories, threat information can significantly influence individuals' threat appraisal and emotions (e.g., fear and anxiety), which can also be influenced by individuals' personality and prior experience (Floyd et al., 2000; Witte, 1992). Furthermore, fear appeal theories also demonstrate that emotions can have an impact on coping appraisals (e.g., motivation to obtain information and to pay attention to information), which can eventually lead to individuals' protective action (So et al., 2016). Therefore, fear appeal theories can help us to understand the effects of the location information of patients (i.e., physical distance to the nearest patients) released during the COVID-19 pandemic on the anxiety, attention to pandemic information and protective behaviors of individuals, as well as the role of citizens' personality (vertical collectivism) in these relationships.

\section{Physical Distance, Vertical Collectivism and Anxiety in Pandemics}

According to fear appeal theories, a fear appeal is defined as a message that presents threat information to cause fear, focusing on the severity and probability of occurrence of a threat to promote safer behavior (Rogers, 1983). Health messages about threats such as fear appeals are widely used in health communication (Ruiter et al., 2014), and varied threat information will cause different levels of negative emotions such as fear and anxiety (Ruiter et al., 2003; Ruiter et al., 2001). For example, messages that focus on the characterization and transmission of tetanus versus the symptoms of the illness and its consequences will induce different levels of psychophysiological responses (e.g., heart rate and skin conductance) (Ordoñana et al., 2009).

Based on the above arguments, we claim that threat information during COVID-19, especially information about people's distance from the nearest confirmed patients, will provoke citizens' anxiety. The physical distance to the specific threat largely determines its degree of severity and possible negative consequences. Research has demonstrated that people show higher levels of fear and anxiety when they perceive a greater severity or possibility of negative consequences from threat information
(Ruiter et al., 2014). Thus, people's fear or anxiety can be influenced by the physical distance to the threat implied by the threat information. For example, Manabe et al. (2012) found that H5N1 patients present in nearer neighboring areas can lead to higher panic in residents. Qian et al. (2003) also reported that when the spatial distance between SARS cases decreases, people show more negative emotions, such as tension, panic, anger, pessimism and helplessness. A possible reason for this might be that a shorter physical distance to confirmed or suspected cases always implies a greater possibility of contact with these infected neighbors. Because living environments are much closer together, neighbors share a common public activity space. Therefore, the smaller the distance is, the greater the possibility of infection, which leads to higher anxiety.

Based on the above arguments, we provide the following hypothesis:

Hypothesis 1: Physical distance to the nearest patients is negatively related to citizens' anxiety; that is, a shorter distance to patients will provoke higher levels of anxiety in citizens.

Additionally, in line with fear appeal theories, individuals' personality can also influence their threat appraisal (Floyd et al., 2000). We propose collectivism, specifically vertical collectivism, to be one of the significant dispositions in the pandemic. Although vertical and horizontal collectivism both emphasize interpersonal relationships, they differ in that vertical collectivism focuses on relationships with one's parents, whereas horizontal collectivism refers to relationships with others, such as colleagues (Rodriguez Mosquera, 2018).

On the one hand, we believe that citizens with a high level of vertical collectivism show lower levels of anxiety during the COVID-19 pandemic. During the early period of the outbreak of the COVID-19 pandemic, owing to the absence of vaccines and antivirals, the best way to interrupt human-tohuman transmission and halt the pandemic worldwide was the implementation of traditional public health measures, such as isolation, quarantine, social distancing and community containment (Wilder-Smith \& Freedman, 2020). As this outbreak of COVID-19 coincided with Chinese New Year, many people stayed home with their families during this period of the pandemic (Chen et al., 2020). Therefore, staying home was more acceptable for people with a high level of vertical collectivism than for people with a low level of vertical collectivism. Furthermore, the acceptance of self-isolation at home reduces the possibility of contact with suspected or unrecognized infected cases. Self-isolation at home weakens anxiety. For this reason, we hypothesize the following:

Hypothesis 2: Vertical collectivism is negatively related to anxiety; that is, citizens with a higher level of vertical collectivism show a lower level of anxiety. 
On the other hand, we claim that vertical collectivism will strengthen the effect of physical distance to confirmed cases on citizens' anxiety. Citizens with a higher level of vertical collectivism care about their families and acknowledge their identity and interdependence with their family in-group (Komarraju \& Cokley, 2008). When confirmed COVID-19 cases are identified in the neighboring area, citizens with a higher level of vertical collectivism will care about the safety of not only themselves but also their families. Thus, the anxiety brought about by patients being present in the neighboring area will be stronger. For this reason, we hypothesize the following:

Hypothesis 3: Citizens' vertical collectivism will strengthen the negative relationship between physical distance and anxiety, and this relationship is stronger when the level of vertical collectivism is high.

\section{Relationship between Anxiety, Attention to Information and Preventive Behaviors}

The fear appeal framework also states that greater fear and anxiety led to increased motivation to obtain protectionrelated information and heightened attention to such information (So et al., 2016, 2019). This statement is consistent with previous research. For example, Li, Chang, et al. (2020) found that major public health emergencies and natural disasters, such as SARS and COVID-19, can cause massive panic and result in greater demands for information.

In periods of pandemics, such as SARS, citizens pay more attention to media information and believe that the government should broadcast pandemic-related information every day (Qian et al., 2003). Basch et al. (2020b) stated that anxiety or panic acts as a catalyst for information seeking. On the one hand, for self-protection purposes, panicked citizens are more eager to seek more information about pandemics because the media offers people a good understanding of a pandemic's prevalence and nature (Zhu et al., 2008). More importantly, some real-time information, including about new COVID-19 cases and their activity tracking, can largely help residents understand the development of pandemics locally and avoid contact with the communities in which patients live or public places that patients visit (Bento et al., 2020).

Thus, we hypothesize the following:

Hypothesis 4: Citizens' anxiety is positively related to their attention to information; that is, citizens with a higher level of anxiety will pay more attention to information concerning COVID-19 than will citizens with a lower level of anxiety.
According to fear appeal theories, individuals' protective behaviors are the consequences of decision processes in which their evaluation of their conditions is part of the decision matrix. This statement is also in line with social cognitive theory (SCT). According to SCT, individuals learn from their interactions with the environment through their experiences, which results in specific behaviors (Attiq, 2015).

In the context of pandemics or other disasters, people pay more attention to relevant information, and they know more about the severity of the pandemic and the importance of taking relevant protective measures (Zhu et al., 2008). Focusing on COVID-19, Bento et al. (2020) claimed that people seek information on what they can and should do in response to the epidemic. Qazi et al. (2020) also stated that information will influence the public's situational awareness of adopting health-protective behaviors such as social distancing. Thus, we hypothesize as follows:

Hypothesis 5: Attention to information is positively related to citizens' preventive behaviors, that is, the more attention that citizens pay to information, the higher the level of preventive behaviors that they exhibit.

Based on the arguments in Hypotheses 4 and 5, we hypothesize the following:

Hypothesis 6: Citizens' attention to information will mediate the positive relationship between their anxiety and preventive behaviors.

Overall, based on fear appeal theories, we propose a theoretical model (Fig. 1) in which physical distance, informed by the location information of patients, is negatively related to citizens' anxiety, and citizens' anxiety, in turn, can improve preventive behaviors through the mediating role of attention to information. In addition, vertical collectivism can reduce anxiety directly, but it can also strengthen the effect of physical distance on anxiety.

\section{Pilot Study}

\section{Self-Developed Measures}

Because there is no existing scale to measure citizens' attention to information and preventive behavior during the COVID-19 pandemic, we developed our own scales. Attention to information was measured by three items that we developed. An example is "I wish I could read every piece of information about the epidemic." Preventive behaviors were measured by three items that we developed. We listed three main types of public preventive behaviors (i.e., wearing a mask, washing hands, and disinfecting) and asked the 
Fig. 1 The proposed model

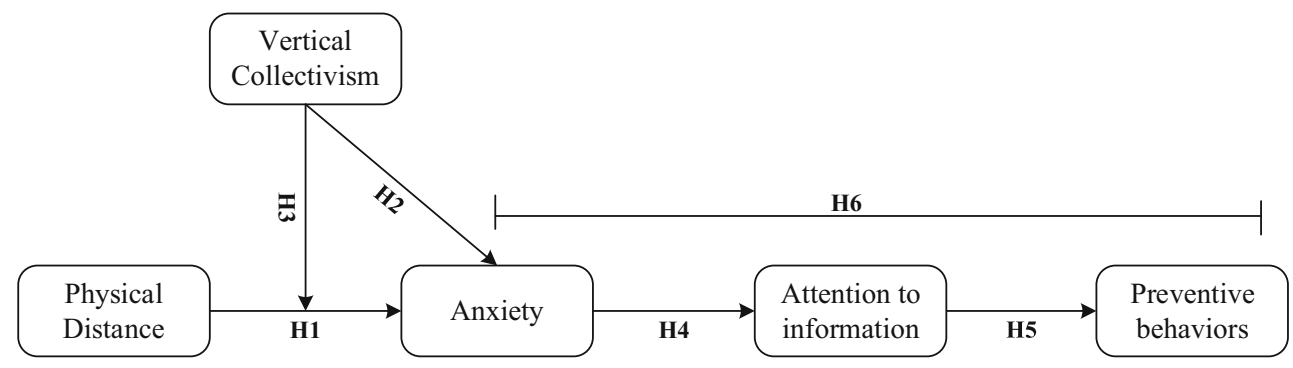

participants to report the frequency with which they exercised these measures when they went out or returned home during the pandemic. These two measures were rated using a 7-point Likert scale ranging from $1=$ strongly disagree/never to $7=$ strongly agree/every time.

\section{Procedure and Participants}

To test the reliability of the new measures that we developed by performing exploratory factor analysis (EFA), as Hinkin (1995) suggested, we conducted a pilot study (i.e., the first round of survey). In the first round of the survey, we only collected data concerning participants' sociodemographic information (e.g., age, gender and education) and selfdeveloped measures (i.e., attention to information and preventive behaviors). As the Chinese government recommended that the public minimize face-to-face interaction and engage in self-isolation, questionnaire surveys in this research were distributed to the potential respondents through an online survey platform ("SurveyStar", Changsha Ranxing Science and Technology, Shanghai, China), and all participants started their online questionnaire after agreeing with the informed consent.

We distributed the e-questionnaire through one of the most popular social software platforms (WeChat) among Chinese residents from February 27-March 3, 2020. A total of 243 participants were involved in this round of surveying. The specific demographic characteristics of the participants in this round of the survey are shown in Table 1.

\section{Data Analysis and Results}

We used exploratory factor analysis (EFA) to test the selfdeveloped measures of attention to information and preventive behaviors during the pandemic (Hinkin, 1995) using SPSS 22.0 (IBM SPSS Statistics, New York, United States). First, to prepare for EFA, we performed reliability tests and item purification using Cronbach's alpha and corrected-item total correlation (CITC). Second, to test whether the data are suitable for EFA, the Kaiser-Meyer-Olkin (KMO) and Bartlett sphericity tests were adopted. Finally, EFA was performed on data collected from the first-round survey to test factor structure (Jarvis et al., 2003). The results of the analysis of the self-developed measures are shown in Table 2.

According to the suggestion of Nunnally (1978), Cronbach's alpha of the scale should be greater than 0.6 , and the CITC index should not be lower than 0.5 . The results in Table 2 meet the above criteria, confirming that all items can be kept. Second, the Bartlett sphericity test results $(p<0.00)$ indicate a high correlation among items, and the KMO value is 0.92 (greater than 0.7 ), showing that the partial correlation between items is good. Therefore, the data are suitable for factor analysis. Last, each item belongs to one factor generated by the EFA with a loading value exceeding 0.8 , which indicates that the items of each variable converged as a separate construct (Nunnally, 1978). The total variance explained exceeds $70 \%$. Therefore, the self-developed measures of the two variables are acceptable.

Table 1 Demographics of the Data Sample

\begin{tabular}{|c|c|c|c|}
\hline \multirow[t]{2}{*}{ Variables } & \multirow[t]{2}{*}{ Characteristics } & \multicolumn{2}{|l|}{$\mathbf{N}$} \\
\hline & & Round 1 & Round 2 \\
\hline \multirow[t]{2}{*}{ Gender } & Male & 104 & 948 \\
\hline & Female & 139 & 1113 \\
\hline \multirow[t]{7}{*}{ Age } & Less than 18 & 26 & 89 \\
\hline & $18-25$ & 90 & 772 \\
\hline & $26-30$ & 42 & 448 \\
\hline & $31-40$ & 53 & 505 \\
\hline & $41-50$ & 22 & 177 \\
\hline & $51-60$ & 9 & 61 \\
\hline & Over 60 & 1 & 9 \\
\hline \multirow[t]{4}{*}{ Education } & Junior high school or below & 25 & 64 \\
\hline & High school & 22 & 219 \\
\hline & Bachelor or college & 127 & 1158 \\
\hline & Master or above & 69 & 620 \\
\hline \multirow[t]{2}{*}{ Location Type } & Urban & 183 & 1562 \\
\hline & Rural & 60 & 499 \\
\hline \multirow[t]{2}{*}{ Location } & Wuhan & 117 & 984 \\
\hline & Non-Wuhan & 126 & 1077 \\
\hline \multicolumn{2}{|c|}{ Total sample size } & 243 & 2061 \\
\hline
\end{tabular}


Table 2 Results of the EFA $(N=243)$

\begin{tabular}{|c|c|c|c|c|c|c|c|c|}
\hline \multirow[t]{2}{*}{ Variables } & \multirow[t]{2}{*}{ Items } & \multirow[t]{2}{*}{ Loading } & \multirow[t]{2}{*}{ CITC } & \multirow{2}{*}{$\begin{array}{l}\text { Cronbach } \\
\alpha\end{array}$} & \multirow[t]{2}{*}{ KMO } & \multicolumn{3}{|c|}{ Bartlett sphericity test } \\
\hline & & & & & & $\begin{array}{l}\text { Approx. Chi- } \\
\text { Square }\end{array}$ & $d f$ & Sig. \\
\hline \multirow[t]{3}{*}{$\begin{array}{l}\text { Preventive } \\
\text { behaviors }\end{array}$} & $\begin{array}{l}\text { When you go out during this outbreak, how often do you: } \\
\text { 1. Wear a mask? }\end{array}$ & 0.905 & 0.777 & 0.858 & 0.738 & 362.618 & 3 & 0.000 \\
\hline & 2. Disinfect yourself? & 0.887 & 0.746 & & & & & \\
\hline & 3. Wash your hands? & 0.884 & 0.735 & & & & & \\
\hline \multirow[t]{3}{*}{$\begin{array}{l}\text { Attention to } \\
\text { information }\end{array}$} & $\begin{array}{l}\text { 1. I cannot wait to read every piece of information about the } \\
\text { epidemic situation. }\end{array}$ & 0.866 & 0.702 & 0.857 & 0.726 & 330.503 & 3 & 0.000 \\
\hline & $\begin{array}{l}\text { 2. Every day when I get up, I cannot wait to hear the latest } \\
\text { development about the epidemic. }\end{array}$ & 0.903 & 0.768 & & & & & \\
\hline & $\begin{array}{l}\text { 3. The most important thing I care about now is information } \\
\text { about the epidemic. }\end{array}$ & 0.877 & 0.721 & & & & & \\
\hline
\end{tabular}

\section{Main Study}

\section{Procedure and Participants}

To further evaluate the self-developed measures and to test the hypotheses developed in this research, we conducted the main study employing another online questionnaire survey. In this round of data collection, we investigated all needed variables. To ensure the reasonableness of the sampling and overcome the limitations regarding face-to-face contact restrictions, we used the SurveyStar Company (Changsha Ranxing Science and Technology, Shanghai, China) to help us collect data. SurveyStar is the largest data collection platform and has a trustworthy data collection service in China. In addition, to check the attentiveness of the participants, we adopted two strategies to keep participants from answering carelessly: 1) setting up reverse-scored questions and 2) using screening items (e.g., "There are 28 hours in a day"). We eliminated invalid answers for the purpose of ensuring the validity of the collected data. The second questionnaire survey was distributed to Chinese residents from March 9-17, 2020, when the spread of COVID-19 was at its peak in China. A total of 2543 Chinese people in China completed our questionnaire. After the data cleaning process, we eventually obtained 2061 valid responses from 244 cities across 30 provinces in China, yielding a response rate of $81.05 \%$. The specific demographic characteristics of the participants in the second round of surveys are also shown in Table 1.

\section{Measures}

All the latent variables in this research were measured using a 7-point Likert scale ranging from $1=$ strongly disagree/unfit/ never to $7=$ strongly agree/fit/every time.
Physical distance was self-reported by asking the participants to describe their distance from the nearest confirmed case as $1=$ less than $200 \mathrm{~m}, 2=200 \mathrm{~m}-1 \mathrm{~km}, 3=1-5 \mathrm{~km}$, $4=5-10 \mathrm{~km}, 5=10-20 \mathrm{~km}, 6=20-50 \mathrm{~km}, 7=$ more than $50 \mathrm{~km}$, or $0=$ not sure. Participants who reported "not sure" were deleted from the final data analysis. We adopted this method for several reasons. First, this research focused on the effects of the location information of patients. However, the availability of and attention to this information are different for individuals, and subjective distance predicts an individual's interaction better than objective distance (Siebdrat et al., 2014). Hence, we asked the participants to report distances themselves. Second, because the participants might not be able to give an accurate estimation of distance, we provided interval distance data to the participants and let them choose what they think is the best. Third, although we claimed that physical distance from patients is negatively related to citizens' anxiety, this relationship should not be linear. For example, controlling for other possible influencing factors, citizens living $1 \mathrm{~km}$ away from patients were very likely to have higher levels of anxiety than citizens living $5 \mathrm{~km}$ away from patients. However, citizens living $26 \mathrm{~km}$ away from patients will likely have a similar level of anxiety as those living $30 \mathrm{~km}$ away from patients, although their distance differences are both $4 \mathrm{~km}$. Previous studies will standardize physical distance values by using log transformation of objective distance (e.g., Siebdrat et al., 2014). Thus, instead of using an equidistant scale, we used a scale with increasing spacing, which is nearly in line with $\log$ transformation.

Anxiety was measured with 5 items from the short-form of the state anxiety scale of the Spielberger State-Trait Anxiety Inventory (STAI), which was developed by Marteau and Bekker (1992). We asked the participants to what extent certain emotions (i.e., feeling calm, tense, upset, relaxed, and worried) matched their actual feelings during the pandemic. 
Vertical collectivism was measured with 4 items developed by Triandis and Gelfand (1998). A sample item is "Family members should stick together, no matter what sacrifices are required". Attention to information and preventive behaviors were measured by items that we developed in the pilot study.

Control variables were included according to suggestions from previous studies. First, we controlled for the sociodemographic variables of the participants, including age, gender, education, location, and location type, following the suggestions from Wang, Pan, Wan, Tan, Xu, Ho, et al. (2020). Additionally, we controlled for relational distance (we asked the respondents to indicate whether they or their relatives had been infected by COVID-19), confidence in overcoming this pandemic, and the controllability of this pandemic, which were suggested to have significant impacts on citizens' emotions and preventive behaviors.

\section{Data Analysis Strategies}

First, we used confirmatory factor analysis (CFA) to further test the new measures of attention to information and preventive behaviors, which were developed in the pilot study. Then, the descriptive statistics and correlation analysis were calculated. Cronbach's alpha, KMO, Bartlett sphericity test, composite reliability (CR), and average variance extracted (AVE) were adopted to examine the construct reliability and validity of key variables using SPSS 22.0 (IBM SPSS Statistics, New York, United States). In addition, CFA was used to test the measurement model and to address the common-method bias caused by self-reporting using a Harman one-factor test (Podsakoff et al., 2003). Finally, we adopted hierarchical regression analysis to test associations of focal variables in the hypothesized model (Hypotheses 1-5) and used path analysis to empirically test the mediation effect (Hypothesis 6). The hypotheses were tested by using Mplus 7.4 software following the procedures proposed by Klein and Moosbrugger (2000).

\section{Results}

\section{Test of the Self-Developed Measures}

To further verify the reliability of the EFA results in the pilot study, CFA was carried out with the second-round samples in Mplus 7.4. The results of the CFA for the variables rated by self-developed measures reached an acceptable level. Specifically, chi-square $\left(\chi^{2}\right)=43.568$, with degrees of freedom $(d f)=8$, comparative fit index $(\mathrm{CFI})=0.991$, TuckerLewis index $(\mathrm{TLI})=0.983$, root mean square error of approximation $($ RMSEA $)=0.046$ and standardized root mean square residual $(\mathrm{SRMR})=0.026$.

\section{Preliminary Analysis}

Table 3 provides the means, standard deviations, and intercorrelations for the sociodemographic characteristics, psychological states and preventive behaviors of the respondents involved in the second round of surveys during the COVID-19 pandemic. The Pearson correlation coefficients in Table 3 show that the variables demonstrate moderate correlations with no overlap, preliminarily providing a basis for the model's assumptions.

Based on the data obtained from the second round of surveys, the reliability and validity of the scale were calculated using SPSS 22.0 software. On the one hand, as shown in Table 3, the Cronbach's alpha coefficients of all the focal variables are higher than .70 , which proves that the scale has good reliability and passes the internal consistency test. On the other hand, the KMO values of all the latent variables are greater than .60 (ranging from 0.66 to 0.76). The Bartlett sphericity test of each variable is significant, and all the factor loadings are greater than .50 . The composite reliability (CR) estimates range from 0.84 to 0.91 , which are ideally acceptable at more than 0.70 (Fornell \& Larcker, 1981). These results thereby confirm that these scales have good reliability. Convergent validity was tested by average variance extracted (AVE), and the AVE values for vertical collectivism, public anxiety, preventive behaviors, and attention to information were $0.58,0.52,0.65$, and 0.76 , respectively, which are all higher than 0.5 (Fornell \& Larcker, 1981). Discriminant validity was assessed by comparing the square of the construct correlation with the AVE values, and the AVE values exceeded the square of the correlation among these three variables. Overall, the measures of the three latent variables in this research have acceptable validity and reliability.

\section{Measurement Model}

CFAs were adopted to examine the construct validity of the focal variables. We found that our hypothesized four-factor model (anxiety, vertical collectivism, attention to information, preventive behaviors $)$ is a better fit for the data $\left(\chi^{2}=669.55\right.$, $d f=84, \mathrm{CFI}=.94, \mathrm{TLI}=.92, \mathrm{RMSEA}=.06, \mathrm{SRMR}=.04)$ than the other 6 constrained models, in which any two of the four factors were combined $\left(1339.57 \leq \Delta \chi^{2}(\Delta d f=3) \leq\right.$ $2700.54, p s<.001)$. In addition, the measures were all selfreported, which may have introduced the possibility of common method variance (Podsakoff et al., 2003). Thus, we also conducted a CFA in which all items of multiple-item variables loaded on one latent factor. The results show that the onefactor model poorly fits the data $\left(\chi^{2}=6641.10, d f=90\right.$, $\mathrm{CFI}=.28$, TLI $=.16$, RMSEA $=.19$, SRMR $=.17)$. Therefore, common method bias was not a significant problem in the study. 
Table 3 Descriptive statistics, correlations and reliabilities of the main variables

\begin{tabular}{|c|c|c|c|c|c|c|c|c|c|c|c|c|c|c|c|}
\hline Variables & Mean & SD & 1 & 2 & 3 & 4 & 5 & 6 & 7 & 8 & 9 & 10 & 11 & 12 & 13 \\
\hline 1. Age & 3.06 & 1.21 & - & & & & & & & & & & & & \\
\hline 2. Gender & .54 & .50 & $-.13^{* *}$ & - & & & & & & & & & & & \\
\hline 3. Education & 3.13 & .72 & $.14^{* *}$ & -.00 & - & & & & & & & & & & \\
\hline 4. Location & .48 & .50 & $-.13^{* *}$ & .02 & $-.41^{* * *}$ & - & & & & & & & & & \\
\hline 5. Location Type & .24 & .43 & $-.28^{* *}$ & .00 & $-.17^{* *}$ & $.12^{* *}$ & - & & & & & & & & \\
\hline 6. Relational Distance & .14 & .35 & $.05^{*}$ & -.01 & $-.09^{* *}$ & $.34^{* *}$ & $-.06^{*}$ & - & & & & & & & \\
\hline 7. Confidence & 6.01 & 1.43 & -.02 & .03 & .00 & $-.05^{*}$ & .00 & $-.06^{* *}$ & - & & & & & & \\
\hline 8. Controllability & 5.93 & 1.13 & $.05^{*}$ & -.04 & -.02 & $-.06^{* *}$ & -.03 & $-.09^{* *}$ & $.25^{* *}$ & - & & & & & \\
\hline 9. Physical Distance & 4.18 & 1.84 & $-.12^{* *}$ & .03 & $-.06^{* *}$ & $-.22^{* *}$ & $.19^{* * *}$ & $-.28^{* *}$ & $.05^{*}$ & $.05^{*}$ & - & & & & \\
\hline 10. Vertical Collectivism & 5.61 & 1.02 & $.17^{* *}$ & -.02 & .00 & $.10^{* *}$ & -.03 & .04 & $.12^{* *}$ & $.17^{* *}$ & $-.05^{*}$ & $(0.76)$ & & & \\
\hline 11. Anxiety & 3.69 & 1.07 & .02 & $.16^{* *}$ & .04 & $.14^{* *}$ & .02 & $.18^{* *}$ & $-.14^{* * *}$ & $-.21^{* *}$ & $-.24^{* *}$ & $-.07^{* *}$ & $(0.77)$ & & \\
\hline 12. Attention to Information & 4.76 & 1.29 & $.07^{* *}$ & .04 & $-.12^{* * *}$ & $.20^{* *}$ & $.06^{*}$ & $.08^{* *}$ & $.08^{* *}$ & $.11^{* * *}$ & -.03 & $.27^{* *}$ & $.17^{* *}$ & $(0.84)$ & \\
\hline 13. Preventive Behaviors & 6.02 & 1.03 & $.14^{* *}$ & $.07^{* *}$ & $.05^{*}$ & .00 & $-.28^{* *}$ & .04 & $.08^{* *}$ & $.12^{* *}$ & $-.12^{* *}$ & $.12^{* * *}$ & .03 & $.12^{* *}$ & $(0.71)$ \\
\hline
\end{tabular}

Note: Cronbach's alpha coefficients are in brackets. Age: $1=$ less than 18 years old; $2=18-25$ years old; $3=26-30$ years old; $4=31-40$ years old; $5=$ 41-50 years old; $6=51-60$ years old; and $7=$ more than 60 years old. Gender: $0=$ male and $1=$ female. Education: $1=$ junior high school or below; $2=$ high school; $3=$ Bachelor or college; and $4=$ Master or above. Location: $0=$ non-Wuhan, $1=$ Wuhan. Location Type: $0=$ Urban, $1=$ Rural. Physical Distance: $1=$ less than $200 \mathrm{~m} ; 2=200 \mathrm{~m}-1 \mathrm{~km} ; 3=1-5 \mathrm{~km} ; 4=5-10 \mathrm{~km} ; 5=10-20 \mathrm{~km} ; 6=20-50 \mathrm{~km}$; and $7=$ more than $50 \mathrm{~km}$. Relational Distance, $0=$ strangers who have been confirmed or suspected cases, $1=$ people who they know have been confirmed or suspected cases (e.g., self, spouse, parents or offspring, siblings, other relatives, neighbors and acquaintances); ${ }^{* *} p<.01,{ }^{*} p<.05$

\section{Hypothesis Testing}

To test our hypotheses, we adopt hierarchical regression analysis, and the regression results are shown in Table 4 . We introduce the variables step by step to test each hypothesis individually. First, the control variables are introduced in the basic model (i.e., the first model for each dependent variable in Table 4) to rule out their potential influences. Subsequently, we introduced the focal variables that are related to our hypotheses into the models (i.e., the subsequent models for each dependent variable in Table 4). Thus, we can obtain the effect size of the newly added variables on the dependent variables by comparing the change in the R-squared of different models.

As shown in Model $_{2}$ in Table 4, physical distance to confirmed or suspected cases is negatively related to citizens' anxiety $(b=-.11, p<.01)$ after controlling for other potential influencing factors, which supports Hypothesis 1 . On the basis of $\mathrm{Model}_{2}$, vertical collectivism is added to examine the effects of vertical collectivism on anxiety. The latent moderated structural equations (LMS) approach is used to construct the potential interaction between the variables (Klein \& Moosbrugger, 2000). In addition, to reduce the collinearity problem, all the interaction items involved in the analysis are ground-mean centered. The results of Model $_{3}$ in Table 4 show that vertical collectivism has a significant negative effect on citizens' anxiety $(b=-.05, p<.05)$, which is consistent with Hypothesis 2. In addition, the coefficient of the interaction term of physical distance and vertical collectivism on citizens' anxiety was significant $(b=-.03, p<.05)$. According to the results of the simple slope test, which is shown in Fig. 2, the relationship between physical distance and citizens' anxiety was stronger when citizens' vertical collectivism was higher $(b=-.14, p<.001)$ than when it was lower $(b=-.08$, $p<.001)$. This finding supports Hypothesis 3.

As shown in Model $_{5}$ in Table 3, citizens' anxiety is positively related to their attention to information concerning COVID-19 $(b=.24, p<.01)$. Thus, Hypothesis 4 is supported. In addition, as shown in $\mathrm{Model}_{7}$, citizens' attention to information is positively related to citizens' preventive behaviors $(b=.07, p<.01)$, which supports Hypothesis 5 . Additionally, to test Hypothesis 6, we applied a path analysis. Hypothesis 6 proposed that attention to information will mediate the relationship between citizens' anxiety and preventive behaviors according to the AET framework. The results of the path analysis with 10,000 bootstrap samples show that the mediation effect of attention to information was .02 (95\% confidence interval $(\mathrm{CI})=[.01, .03]$ excluding zero), which provides support for Hypothesis 6.

Overall, the above results are summarized in Fig. 3, which shows that all hypotheses in this study have been supported.

\section{Discussion}

Now, we can answer the research question: How does the location information of patients, particularly physical distance to the nearest patients, influence citizens' anxiety, attention to information and preventive behaviors during a pandemic? The results of this research indicate that physical distance to the nearest patients has a significant negative effect on citizens' 
Table 4 Regression results

\begin{tabular}{|c|c|c|c|c|c|c|c|}
\hline \multirow[t]{2}{*}{ Predictors } & \multicolumn{3}{|l|}{ Anxiety } & \multicolumn{2}{|c|}{ Attention to information } & \multicolumn{2}{|c|}{ Preventive Behaviors } \\
\hline & Model $_{1}$ & Model $_{2}$ & Model $_{3}$ & Model $_{4}$ & Model $_{5}$ & Model $_{6}$ & Model $_{7}$ \\
\hline Constant & $\begin{array}{l}4.00^{* *} \\
(0.20)\end{array}$ & $\begin{array}{l}4.62^{* *} \\
(0.21)\end{array}$ & $\begin{array}{l}4.83^{\text {** }} \\
(0.21)\end{array}$ & $\begin{array}{l}2.16^{\text {*** }} \\
(0.27)\end{array}$ & $\begin{array}{l}1.02^{* * *} \\
(0.31)\end{array}$ & $\begin{array}{l}4.71^{* *} \\
(0.26)\end{array}$ & $\begin{array}{l}4.63^{\text {** }} \\
(0.26)\end{array}$ \\
\hline \multicolumn{8}{|l|}{ Control variables } \\
\hline Age & $\begin{array}{l}0.04^{*} \\
(0.02)\end{array}$ & $\begin{array}{l}0.03 \\
(0.02)\end{array}$ & $\begin{array}{l}0.04 \\
(0.02)\end{array}$ & $\begin{array}{l}0.08^{\text {*** }} \\
(0.02)\end{array}$ & $\begin{array}{l}0.07^{* *} \\
(0.02)\end{array}$ & $\begin{array}{l}0.05^{*} \\
(0.02)\end{array}$ & $\begin{array}{l}0.04^{*} \\
(0.02)\end{array}$ \\
\hline Gender $^{\mathbf{a}}$ & $\begin{array}{l}0.35^{\text {** }} \\
(0.05)\end{array}$ & $\begin{array}{l}0.36^{* *} \\
(0.05)\end{array}$ & $\begin{array}{l}0.36^{* *} \\
(0.03)\end{array}$ & $\begin{array}{l}0.14^{\text {*** }} \\
(0.05)\end{array}$ & $\begin{array}{l}0.06 \\
(0.05)\end{array}$ & $\begin{array}{l}0.16^{* *} \\
(0.05)\end{array}$ & $\begin{array}{l}0.15^{\text {** }} \\
(0.05)\end{array}$ \\
\hline Education & $\begin{array}{l}0.14^{\text {** }} \\
(0.04)\end{array}$ & $\begin{array}{l}0.11^{\text {** }} \\
(0.03)\end{array}$ & $\begin{array}{l}0.11^{* * *} \\
(0.03)\end{array}$ & $\begin{array}{l}-0.10^{*} \\
(0.04)\end{array}$ & $\begin{array}{l}-0.13^{* *} \\
(0.04)\end{array}$ & $\begin{array}{l}0.00 \\
(0.03)\end{array}$ & $\begin{array}{l}0.01 \\
(0.03)\end{array}$ \\
\hline Location $^{\mathbf{b}}$ & $\begin{array}{l}0.26^{* *} \\
(0.05)\end{array}$ & $\begin{array}{l}0.17^{* *} \\
(0.05)\end{array}$ & $\begin{array}{l}0.18^{* *} \\
(0.05)\end{array}$ & $\begin{array}{l}0.39^{* *} \\
(0.06)\end{array}$ & $\begin{array}{l}0.35^{* *} \\
(0.06)\end{array}$ & $\begin{array}{l}0.05 \\
(0.05)\end{array}$ & $\begin{array}{l}0.02 \\
(0.05)\end{array}$ \\
\hline Location Type $^{\mathbf{c}}$ & $\begin{array}{l}0.10 \\
(0.05)\end{array}$ & $\begin{array}{l}0.18^{* * *} \\
(0.05)\end{array}$ & $\begin{array}{l}0.18^{* *} \\
(0.05)\end{array}$ & $\begin{array}{l}0.17^{* * *} \\
(0.06)\end{array}$ & $\begin{array}{l}0.13^{*} \\
(0.06)\end{array}$ & $\begin{array}{l}-0.62^{* *} \\
(0.06)\end{array}$ & $\begin{array}{l}-0.63^{\text {** }} \\
(0.06)\end{array}$ \\
\hline Relational Distance $^{\mathbf{d}}$ & $\begin{array}{l}0.40^{\text {** }} \\
(0.07)\end{array}$ & $\begin{array}{l}0.29^{\text {*** }} \\
(0.07)\end{array}$ & $\begin{array}{l}0.28^{\text {** }} \\
(0.07)\end{array}$ & $\begin{array}{l}0.10 \\
(0.08)\end{array}$ & $\begin{array}{l}0.04 \\
(0.08)\end{array}$ & $\begin{array}{l}0.01 \\
(0.07)\end{array}$ & $\begin{array}{l}0.01 \\
(0.07)\end{array}$ \\
\hline Confidence & $\begin{array}{l}-0.06^{* *} \\
(0.02)\end{array}$ & $\begin{array}{l}-0.06^{\text {*** }} \\
(0.02)\end{array}$ & $\begin{array}{l}-0.06^{* *} \\
(0.02)\end{array}$ & $\begin{array}{l}0.04^{*} \\
(0.02)\end{array}$ & $\begin{array}{l}0.05^{* *} \\
(0.02)\end{array}$ & $\begin{array}{l}0.04^{* *} \\
(0.02)\end{array}$ & $\begin{array}{l}0.04^{*} \\
(0.02)\end{array}$ \\
\hline Controllability & $\begin{array}{l}-0.15^{\text {*** }} \\
(0.02)\end{array}$ & $\begin{array}{l}-0.15^{* *} \\
(0.02)\end{array}$ & $\begin{array}{l}-0.14^{* *} \\
(0.02)\end{array}$ & $\begin{array}{l}0.08^{* * *} \\
(0.03)\end{array}$ & $\begin{array}{l}0.11^{* * *} \\
(0.03)\end{array}$ & $\begin{array}{l}0.09^{* *} \\
(0.02)\end{array}$ & $\begin{array}{l}0.08^{* *} \\
(0.02)\end{array}$ \\
\hline \multicolumn{8}{|l|}{ Focal variables } \\
\hline Physical Distance & & $\begin{array}{l}-0.11^{* *} \\
(0.01)\end{array}$ & $\begin{array}{l}-0.11^{* *} \\
(0.01)\end{array}$ & $\begin{array}{l}0.01 \\
(0.02)\end{array}$ & $\begin{array}{l}0.03^{*} \\
(0.02)\end{array}$ & $\begin{array}{l}-0.03^{*} \\
(0.01)\end{array}$ & $\begin{array}{l}-0.03^{*} \\
(0.01)\end{array}$ \\
\hline Vertical collectivism & & & $\begin{array}{l}-0.05^{*} \\
(0.02)\end{array}$ & $\begin{array}{l}0.29^{* * *} \\
(0.03)\end{array}$ & $\begin{array}{l}0.31^{\text {*** }} \\
(0.03)\end{array}$ & $\begin{array}{l}0.08^{* *} \\
(0.02)\end{array}$ & $\begin{array}{l}0.06^{*} \\
(0.02)\end{array}$ \\
\hline Physical Distance $\times$ vertical collectivism & & & $\begin{array}{l}-0.03^{* *} \\
(0.02)\end{array}$ & & & & \\
\hline Anxiety & & & & & $\begin{array}{l}0.24^{\text {*** }} \\
(0.03)\end{array}$ & $\begin{array}{l}0.04 \\
(0.02)\end{array}$ & $\begin{array}{l}0.02 \\
(0.02)\end{array}$ \\
\hline Attention to Information & & & & & & & $\begin{array}{l}0.07^{* *} \\
(0.02)\end{array}$ \\
\hline R-squared & 0.118 & 0.148 & 0.154 & 0.123 & 0.156 & 0.119 & 0.126 \\
\hline$\Delta \mathrm{R}$-squared & & 0.030 & 0.006 & & 0.033 & & 0.007 \\
\hline F value & $34.188^{* *}$ & $39.623^{* *}$ & $33.852^{* *}$ & $28.678^{* *}$ & $34.362^{* *}$ & $25.107^{* *}$ & $24.637^{* *}$ \\
\hline
\end{tabular}

Note: Standard errors in parentheses, $N=2061,{ }^{* *} p<.01,{ }^{*} p<.05$

a dummying variable, $0=$ male, $1=$ female;

${ }^{\mathrm{b}}$ dummying variable, $0=$ non-Wuhan, $1=$ Wuhan;

${ }^{\mathrm{c}}$ dummying variable, $0=$ urban, $1=$ rural;

${ }^{\mathrm{d}}$ dummying variable, $0=$ strangers, $1=$ self, spouse, parents or offspring, siblings, other relatives, neighbors and acquaintances

anxiety. In addition, vertical collectivism can reduce anxiety, but it can also strengthen the effect of physical distance on anxiety. Furthermore, anxiety can improve citizens' preventive behaviors through paying attention to information. These findings provide several theoretical and policy implications.

\section{Theoretical Implications}

First, this study contributes to the health communication literature by revealing the effects of location information of patients as a fear appeal, especially about the physical distance to the nearest patients on citizens during a pandemic. Concerning health communications, to maintain social stability and reduce the negative impacts of health crises on residents, researchers and public administrators have made great efforts to explore the role of epidemic information during the COVID-19 pandemic (Liao \& Wang, 2021) and have focused on different types of information, such as case information or statistical information (Liu et al., 2020). However, the effects of information about where patients were located were neglected. Location information can inform citizens about the physical distance to the nearest patients, and our findings demonstrate 
Fig. 2 Vertical collectivism moderates the negative relationship between physical distance and citizens' anxiety

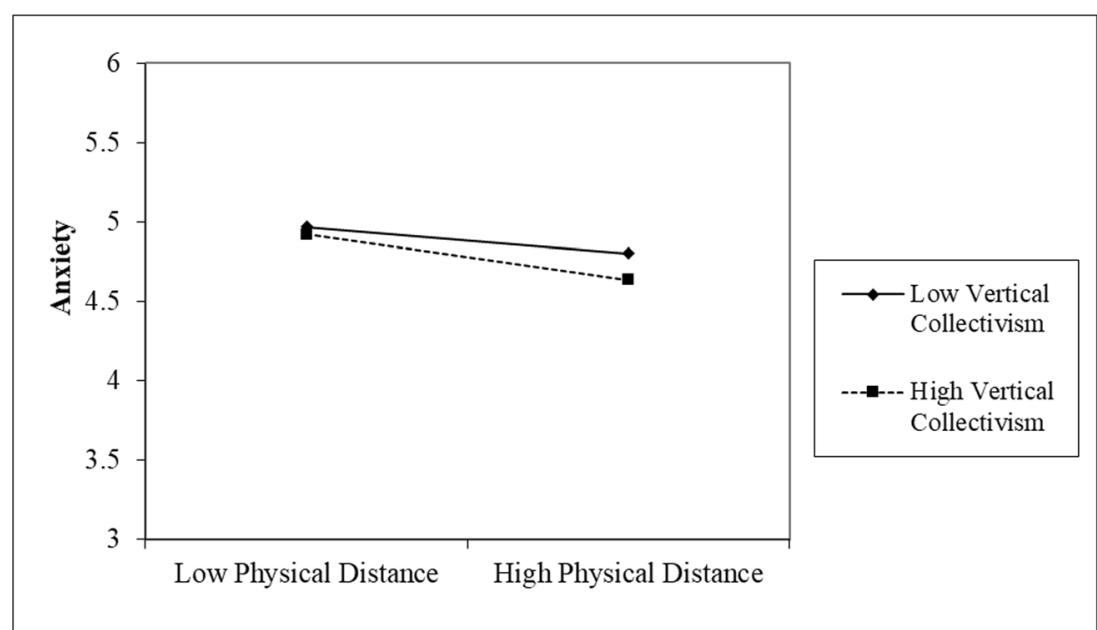

that this type of information, as a fear appeal, can encourage audiences to engage in healthy behaviors.

Second, this research contributes to the public health crisis management literature. To better manage a public health crisis, researchers have separately explored physical distance (Manabe et al., 2012), citizens' anxiety (Wang, Pan, Wan, Tan, Xu, Ho, et al., 2020; Sadeghzadeh et al., 2021), attention to information (Bento et al., 2020) and preventive behaviors (Basch et al., 2020a). This model provides researchers with new perspectives by which to explain the relationship among physical distance, citizens' emotions, attention to information and behaviors, which all tend to emphasize the importance of understanding citizens' reactions in crises (Scott et al., 2015).

Third, this research contributes to fear appeal theories by revealing the effects of vertical collectivism as a personality trait in influencing citizens' threat appraisal about threat information. Fear appeal theories claim that the same fear appeal will produce different perceptions based on the differences in individual personality. The current research reveals the twofold effects of vertical collectivism on fear appeals during the COVID-19 pandemic. On the one hand, citizens with high vertical collectivism are more willing to stay at home with their families (Komarraju \& Cokley, 2008), and they show a lower level of anxiety when they need to self-isolate at home in a crisis, such as during the COVID-19 pandemic. On the other hand, vertical collectivism strengthens the negative relationship between physical distance and anxiety because citizens with high levels of vertical collectivism care more about their families, which leads to additional amounts of anxiety when patients infected with the virus are present in the neighboring area.

Fourth, this research has confirmed the positive effect of anxiety based on fear appeal theories. Usually, scholars in the field of psychology define anxiety as a negative emotion and try to find ways to control it. In this research, we found that anxiety has a positive impact on improving citizens' preventive behaviors during a pandemic, which is conditional on the mediating effect of citizens' attention to information. These findings imply that a moderate level of anxiety is beneficial to citizens, highlighting the significant role of information in public crisis management. These findings not only contribute to the crisis management literature but also help psychology researchers interpret the positive effects of the public's negative psychological states.

\section{Practical and Policy Implications}

This paper also provides significant practical and policy implications. First, our findings show that the presence of patients in a neighboring area can provoke anxiety, which is consistent with the finding of the study by Manabe et al. (2012) that was conducted in the context of H5N1 outbreaks. In this regard, on the one hand, governments should refute rumors that include fake locations of patients to avoid
Fig. 3 Unstandardized estimates of the path coefficients. ${ }^{* *} p<.01$, ${ }^{*} p<.05$

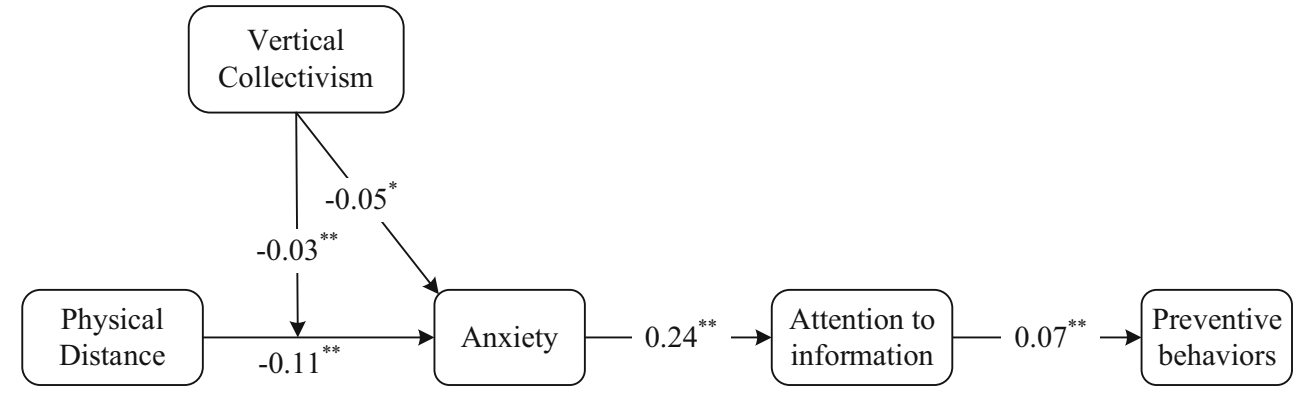


unnecessary anxiety among citizens. On the other hand, local governments should provide the necessary psychological counseling to residents of communities where confirmed patients are located (Zhu et al., 2008). Online trauma-focused psychotherapy has also been proven to be helpful in reducing public anxiety (Wang, Pan, Wan, Tan, Xu, McIntyre, et al., 2020). Regarding offline psychological counseling, community-based organizations can also actively work with local governments to offer these services (Cheng et al., 2020).

In addition, we have proven the mediating role of attention to information in the relationship between citizens' anxiety and preventive behaviors. To make full use of the positive effects of anxiety, governments need to use various channels to disclose epidemic information and provide support for the public's attention to information. More importantly, governments should promptly disclose correct pandemic information and eliminate fake news or misinformation ( $\mathrm{Yu}$ et al., 2005). Only accurate information can guide citizens to engage in the correct preventive behaviors and avoid maladaptive behaviors such as unnecessary trips to emergency rooms or the overuse of other emergency health resources (Basch et al., 2020b). For example, the Chinese government has established rumor modules on social media platforms, such as Weibo and WeChat, to eliminate rumors and incorrect preventive behaviors related to the COVID-19 pandemic. Likewise, the Indian government has also requested top social media companies, such as Facebook, YouTube, TikTok, ShareChat, and Twitter, to stop publishing misinformation (D'Souza et al., 2020).

\section{Limitations and Future Directions}

Although the article synthesizes previous research and investigates the effects of location information of patients on citizens during pandemics based on fear appeal theories, there are still some limitations to the research that need to be resolved by future studies. First, the data we obtained from the survey are cross-sectional, which may lead to the phenomenon of reverse causality in the results (Zhang et al., 2014). As Maio et al. (2018) stated, attitudes can easily change, and crosssectional data cannot clearly reflect the dynamic relationship trend between these variables. Thus, future longitudinal databased studies would be useful for better identifying clear causal relationships among these constructs. Second, another potential limitation stems from citizens' self-reported measures of their own perceptions, which may contain individual perceptual bias (Scopelliti et al., 2021). For example, citizens' self-reported distance from the nearest confirmed case might be different from the actual distance. Because this research focused on the effects of location information of patients, the availability of and attention to this information varies among individuals. Thus, we used self-reported rather than objective data to measure distance because it reflects citizens' reception and interpretation of this information and will better predict individuals' reactions (Siebdrat et al., 2014). However, we still acknowledge this limitation and note that our results should be interpreted in conjunction with more findings from other normative, qualitative, and quantitative studies. Last, because individuals with different preferences for affective and cognitive information will respond to social information differently (Aquino et al., 2020), and attitudes toward others will influence their information processing and behaviors (Maio et al., 2018), it is important for future studies to deepen the roles of individual preferences for affective and cognitive information and attitudes in our model.

\section{Conclusion}

In the context of the COVID-19 pandemic, the issue of how information about the location of patients, i.e., physical distance to the nearest patients, influences citizens' emotions, attention to information and behaviors needs to be addressed. This study was based on fear appeal theories and revealed that a shorter physical distance to patients will provoke higher levels of anxiety, thereby leading to more attention being paid to pandemic information and eventually influencing citizens' preventive behaviors. In addition, citizens' personality, such as vertical collectivism, also plays a critical role in this chain reaction, including reducing citizens' anxiety directly and strengthening the impact of physical distance on anxiety. These findings provide significant evidence-based support for governments to use as they engage in measures to reduce citizens' anxiety and improve their preventive behaviors during this pandemic. In addition, this study also offers measures that the government or the public can apply to reduce anxiety and increase preventive behaviors. Although this chain reaction is proven in the context of COVID-19 in China, the use of this model in other countries or regions needs further testing.

\section{Code Availability Not applicable.}

Authors' Contributions Conceived and designed the study: Guobin Wu, Bingsheng Liu.

Data collecting: Xiaopeng Deng.

Analyzed and discussed the data: Guobin Wu.

Wrote the original draft: Guobin $\mathrm{Wu}$.

Reviewed and edited the paper: Bingsheng Liu, Xiaopeng Deng.

Funding This work was supported by the National Natural Science Foundation of China [grant number 71722004].

Data Availability The data that support the findings of this study are available from the corresponding author upon reasonable request.

\section{Declarations}


Ethics Approval The study was reviewed and approved by the Ethics Committee of Chongqing University.

Conflict of Interest none.

\section{References}

Adhikari, S. P., Meng, S., Wu, Y. J., Mao, Y. P., Ye, R. X., Wang, Q. Z., Sun, C., Sylvia, S., Rozelle, S., Raat, H., \& Zhou, H. (2020). Epidemiology, causes, clinical manifestation and diagnosis, prevention and control of coronavirus disease (COVID-19) during the early outbreak period: A scoping review. Infectious Diseases of Poverty, 9(1), 29. https://doi.org/10.1186/s40249-020-00646-x.

Aquino, A., Alparone, F. R., Pagliaro, S., Haddock, G., Maio, G., Perrucci, M., et al. (2020). Sense or sensibility? The neurofunctional basis of the structural matching effect in persuasion. Cognitive, Affective, \& Behavioral Neuroscience, 20, 536-550. https://doi.org/10.3758/s13415-020-00784-7.

Attiq, S. (2015). Attention to social comparison information and compulsive buying behavior: An S-O-R analysis. Journal of Behavioural Sciences, 25(1), 39-58.

Basch, C. H., Hillyer, G. C., Meleo-Erwin, Z. C., Jaime, C., Mohlman, J., $\&$ Basch, C. E. (2020a). Educating the public about reducing exposure to SARS-CoV-2: Preventive behaviors conveyed on YouTube to mitigate transmission of COVID-19. JMIR Public Health and Surveillance, 6(2), 147-152. https://doi.org/10.2196/18807.

Basch, C. H., Mohlman, J., Hillyer, G. C., \& Garcia, P. (2020b). Public health communication in time of crisis: Readability of on-line COVID-19 information. Disaster Medicine and Public Health Preparedness, 14(5), 635-637. https://doi.org/10.1017/dmp.2020. 151.

Bayham, J., \& Fenichel, E. P. (2020). Impact of school closures for COVID-19 on the US health-care workforce and net mortality: A modelling study. The Lancet Public Health, 5(5), e271-e278. https://doi.org/10.1016/S2468-2667(20)30082-7.

Bento, A. I., Nguyen, T., Wing, C., Lozano-Rojas, F., Ahn, Y.-Y., \& Simon, K. (2020). Evidence from internet search data shows information-seeking responses to news of local COVID-19 cases. Proceedings of the National Academy of Sciences of the United States of America, 117(21), 11220-11222. https://doi.org/10.1073/ pnas. 2005335117.

Chen, S., Yang, J., Yang, W., Wang, C., \& Bärnighausen, T. (2020). COVID-19 control in China during mass population movements at new year. The Lancet, 395(10226), 764-766. https://doi.org/10. 1016/s0140-6736(20)30421-9.

Cheng, Y., Yu, J., Shen, Y., \& Huang, B. (2020). Coproducing responses to COVID-19 with community-based organizations: Lessons from Zhejiang Province, China. Public Administration Review, doi: https://doi.org/10.1111/puar.13244.

Cho, H., Ippolito, D., \& Yu, Y. W. (2020). Contact Tracing Mobile Apps for COVID-19: Privacy Considerations and Related Trade-offs. https://arxiv.org/abs/2003.11511v1.

D'Souza, R. S., D'Souza, S., Strand, N., Anderson, A., Vogt, M. N. P., \& Olatoye, O. (2020). YouTube as a source of medical information on the novel coronavirus 2019 disease (COVID-19) pandemic. Global Public Health, 15, 1-8. https://doi.org/10.1080/17441692.2020. 1761426.

Du, H., Yang, J., King, R. B., Yang, L., \& Chi, P. (2020). COVID-19 increases online searches for emotional and health-related terms. Applied Psychology. Health and Well-Being, 12(4), 1039-1053. https://doi.org/10.1111/aphw.12237.

Floyd, D. L., Prentice-Dunn, S., \& Rogers, R. W. (2000). A meta-analysis of research on protection motivation theory. Journal of Applied
Social Psychology, 30(2), 407-429. https://doi.org/10.1111/j.15591816.2000.tb02323.x.

Fornell, C., \& Larcker, D. F. (1981). Evaluating structural equation models with unobservable variables and measurement error. Journal of Marketing Research, 18(1), 39-50. https://doi.org/10. 1177/002224378101800104.

Hinkin, T. R. (1995). A review of scale development practices in the study of organizations. Journal of Management, 21(5), 967-988. https://doi.org/10.1016/0149-2063(95)90050-0.

Jarvis, C. B., MacKenzie, S. B., \& Podsakoff, P. M. (2003). A critical review of construct indicators and measurement model misspecification in marketing and consumer research. Journal of Consumer Research, 30(2), 199-218. https://doi.org/10.1086/ 376806.

Klein, A., \& Moosbrugger, H. (2000). Maximum likelihood estimation of latent interaction effects with the LMS method. Psychometrika, 65(4), 457-474.

Kok, G., Bartholomew, L. K., Parcel, G. S., Gottlieb, N. H., \& Fernández, M. E. (2014). Finding theory- and evidence-based alternatives to fear appeals: Intervention mapping. International Journal of Psychology, 49(2), 98-107. https://doi.org/10.1002/ijop.12001.

Komarraju, M., \& Cokley, K. O. (2008). Horizontal and vertical dimensions of individualism-collectivism: A comparison of African Americans and European Americans. Cultural Diversity \& Ethnic Minority Psychology, 14(4), 336-343. https://doi.org/10.1037/ 1099-9809.14.4.336.

Kuo, P. C., Huang, J. H., \& Liu, M. D. (2011). Avian influenza risk perception and preventive behavior among traditional market workers and shoppers in Taiwan: Practical implications for prevention. PLoS One, 6(9), e24157. https://doi.org/10.1371/journal.pone. 0024157.

Li, G., Chang, B., Li, H., Wang, R., \& Li, G. (2020). The role of dental professionals in pandemic events and disasters response. Disaster Medicine and Public Health Preparedness, 1-13, doi:https://doi. org/10.1017/dmp.2020.140.

Li, H., Chen, X., \& Huang, H. (2020). The novel coronavirus outbreak: What can be learned from China in public reporting? Global Health Research and Policy, 5, 9. https://doi.org/10.1186/s41256-02000140-9.

Liao, H.-P., \& Wang, J.-L. (2021). The impact of epidemic information on the public's worries and attitude toward epidemic prevention measures during the COVID-19 outbreak. Current Psychology. https://doi.org/10.1007/s12144-021-01364-9.

Ling, M., Kothe, E. J., \& Mullan, B. A. (2019). Predicting intention to receive a seasonal influenza vaccination using protection motivation theory. Social Science \& Medicine, 233, 87-92. https://doi.org/10. 1016/j.socscimed.2019.06.002.

Liu, B., Lin, S., Wang, Q., Chen, Y., \& Zhang, J. (2020). Can local governments' disclosure of pandemic information decrease residents' panic when facing COVID-19 in China? International Public Management Journal, Published online, https://doi.org/10. 1080/10967494.10962020.11840463

Maddux, J. E., \& Rogers, R. W. (1983). Protection motivation and selfefficacy: A revised theory of fear appeals and attitude change. Journal of Experimental Social Psychology, 19(5), 469-479. https://doi.org/10.1016/0022-1031(83)90023-9.

Maio, G. G. R., Haddock, G., \& Verplanken, B. (2018). The psychology of attitudes and attitude change: Sage.

Manabe, T., Hanh, T. T., Lam, D. M., Van, D. T. H., Thuy, P. T. P., Huyen, D. T. T., et al. (2012). Knowledge, attitudes, practices and emotional reactions among residents of avian influenza (H5N1) hit communities in Vietnam. PLoS One, 7(10), e47560. https://doi.org/ 10.1371/journal.pone.0047560.

Marteau, T. M., \& Bekker, H. (1992). The development of a six-item short-form of the state scale of the Spielberger state-trait anxiety 
inventory (STAI). Brifish Journal of Clinical Psycbhology, 31(3), 301-306. https://doi.org/10.1111/j.2044-8260.1992.tb00997.x.

Nunnally, J. D. (1978). Psychometric Theory (second ed.). New York, NY.: McGrawHill.

Ordoñana, J. R., González-Javier, F., Espín-López, L., \& Gómez-Amor, J. (2009). Self-report and psychophysiological responses to fear appeals. Human Communication Research, 35(2), 195-220, doi: https://doi.org/10.1111/j.1468-2958.2009.01344.x \%j human communication research.

Podsakoff, P. M., MacKenzie, S. B., Lee, J.-Y., \& Podsakoff, N. P. (2003). Common method biases in behavioral research: A critical review of the literature and recommended remedies. Journal of Applied Psychology, 88(5), 879-903.

Qazi, A., Qazi, J., Naseer, K., Zeeshan, M., Hardaker, G., Maitama, J. Z., \& Haruna, K. (2020). Analyzing situational awareness through public opinion to predict adoption of social distancing amid pandemic COVID-19. Journal of Medical Virology, 92, 849-855. https://doi. org/10.1002/jmv.25840.

Qian, M., Ye, D., \& Dong, W. (2003). Behaviour, cognition and emotion of the public in Beijing towards SARS. Chinese Mental Health Journal, 17(8), 515-520.

Rochadi, A. S., Putri, N. A., \& Fauzi, Z. A. (2020). Public panic over Covid-19 outbreak: Criticism toward panic theory in collective behavior study. Technium Social ences Journal, 10(1), 544-552.

Rodriguez Mosquera, P. M. (2018). Cultural concerns: How valuing social-image shapes social emotion. European Review of Social Psychology, 29(1), 1-37. https://doi.org/10.1080/10463283.2017. 1412180.

Rogers, R. W. (1975). A protection motivation theory of fear appeals and attitude Change1. The Journal of Psychology, 91(1), 93-114. https://doi.org/10.1080/00223980.1975.9915803.

Rogers, R. W. (1983). Cognitive and physiological processes in fear appeals and attitude change: A revised theory of protection motivation. In J. Cacioppo \& R. Petty (Eds.), Social psychophysiology: A sourcebook (pp. 153-177). Guilford Press.

Ruiter, R. A. C., Kok, G., Verplanken, B., \& Brug, J. (2001). Evoked fear and effects of appeals on attitudes to performing breast self-examination: An information-processing perspective. Health Education Research, 16(3), 307-319. https://doi.org/10.1093/her/16.3.307.

Ruiter, R. A. C., Kessels, L. T. E., Peters, G.-J. Y., \& Kok, G. (2014). Sixty years of fear appeal research: Current state of the evidence. International Journal of Psychology, 49(2), 63-70. https://doi.org/ 10.1002/ijop. 12042.

Ruiter, R. A. C., Verplanken, B., Kok, G., \& Werrij, M. Q. (2003). The Role of Coping Appraisal in Reactions to Fear Appeals: Do We Need Threat Information? , 8(4), 465-474, doi:https://doi.org/10. 1177/13591053030084006.

Sadeghzadeh, M., Abbasi, M., Khajavi, Y., \& Amirazodi, H. (2021). Psychological correlates of anxiety in response to COVID-19 outbreak among Iranian University students. Current Psychology. https://doi.org/10.1007/s12144-020-01237-7.

Scopelliti, M., Pacilli, M., \& Aquino, A. (2021). TV news and COVID19: Media influence on healthy behavior in public spaces. International Journal of Environmental Research and Public Health, 18, 1879. https://doi.org/10.3390/ijerph18041879.

Scott, D., Shankar Sankaran, P., Brandow, C., Hobbins, J., Nilsson, S., \& Enander, A. (2015). Capturing the citizen perspective in crisis management exercises: Possibilities and challenges. International Journal of Emergency Services, 4(1), 86-102. https://doi.org/10. 1108/ijes-12-2014-0024.

Siebdrat, F., Hoegl, M., \& Ernst, H. (2014). Subjective distance and team collaboration in distributed teams. Journal of Product Innovation Management, 31(4), 765-779. https://doi.org/10.1111/jpim.12122.

So, J. (2013). A further extension of the extended parallel process model (E-EPPM): Implications of cognitive appraisal theory of emotion and dispositional coping style. Health Communication, 28(1), 72 83. https://doi.org/10.1080/10410236.2012.708633.

So, J., Kuang, K., \& Cho, H. (2016). Reexamining fear appeal models from cognitive appraisal theory and functional emotion theory perspectives. Communication Monographs, 83(1), 120-144. https:// doi.org/10.1080/03637751.2015.1044257.

So, J., Kuang, K., \& Cho, H. (2019). Information seeking upon exposure to risk messages: Predictors, outcomes, and mediating roles of health information seeking. Communication Research, 46(5), 663687. https://doi.org/10.1177/0093650216679536.

Triandis, H. C., \& Gelfand, M. J. (1998). Converging measurement of horizontal and vertical individualism and collectivism. Journal of Personality \& Social Psychology, 74(1), 118-128.

Tuo, J., Hai-Lian, C., Jing, X., Ling-Ning, W., Jie-Jia, L., Kai, C., et al. (2020). Lockdown contained the spread of 2019 novel coronavirus disease in Huangshi city, Early epidemiological findings. Clinical Infectious Diseases.

Wang, C., Pan, R., Wan, X., Tan, Y., Xu, L., Ho, C. S., \& Ho, R. C. (2020). Immediate psychological responses and associated factors during the initial stage of the 2019 coronavirus disease (COVID-19) epidemic among the general population in China. International Journal of Environmental Research and Public Health, 17(5), 1729. https://doi.org/10.3390/ijerph17051729.

Wang, C., Pan, R., Wan, X., Tan, Y., Xu, L., McIntyre, R. S., Choo, F. N., Tran, B., Ho, R., Sharma, V. K., \& Ho, C. (2020). A longitudinal study on the mental health of general population during the COVID19 epidemic in China. Brain, Behavior, and Immunity, 87, 40-48. https://doi.org/10.1016/j.bbi.2020.04.028.

WHO (2020). WHO Director-General's opening remarks at the media briefing on COVID-19 - 11 March 2020. (2020/4/15), https:// www.who.int/dg/speeches/detail/who-director-general-s-openingremarks-at-the-media-briefing-on-covid-19\%2D\%2D-11-march2020.

Wilder-Smith, A., \& Freedman, D. O. (2020). Isolation, quarantine, social distancing and community containment: Pivotal role for old-style public health measures in the novel coronavirus (2019-nCoV) outbreak. Journal of Travel Medicine, 27(2). https://doi.org/10.1093/ $\mathrm{jtm} / \mathrm{taaa} 020$.

Witte, K. (1992). Putting the fear back into fear appeals: The extended parallel process model. Communication Monographs, 59(4), 329349. https://doi.org/10.1080/03637759209376276.

Wu, Z., \& McGoogan, J. M. (2020). Characteristics of and important lessons from the coronavirus disease 2019 (COVID-19) outbreak in China: Summary of a report of 72314 cases from the Chinese Center for Disease Control and Prevention. Journal of the American Medical Association, 323(13), 1239-1242. https://doi.org/10.1001/ jama.2020.2648

Yu, H. Y. R., Ho, S. C., So, K. F. E., \& Lo, Y. L. (2005). Short communication: The psychological burden experienced by Hong Kong midlife women during the SARS epidemic. Stress and Health, 21(3), 177-184. https://doi.org/10.1002/smi.1051.

Zastrow, M. (2020). South Korea is reporting intimate details of COVID19 cases: Has it helped? Nature, https://doi.org/10.1038/d4158641020-00740-y, doi:https://doi.org/10.1038/d41586-020-00740-y.

Zhang, X., Hu, B., \& Qiu, M. (2014). Job satisfaction as a mediator in the relationship between performance appraisal and voice behavior. Social Behavior and Personality: An International Journal, 42(8), 1315-1323.

Zhu, X., Wu, S., Miao, D., \& Li, Y. (2008). Changes in emotion of the Chinese public in regard to the Sars period. Social Behavior \& Personality, 36(4), 447-454.

Publisher's Note Springer Nature remains neutral with regard to jurisdictional claims in published maps and institutional affiliations. 